\title{
Surgical-site infection risk in oncologic digestive surgery
}

\begin{abstract}
Surgical-site infection (SSI) is the most prevalent type of hospital infection in surgical patients and is associated with an increase in hospital stay, costs and morbidity/lethality. The knowledge of the main risk factorsforthistypeofinfectionisimportantfortheestablishmentofpreventionmeasuresregardingmodifiable risks factors. The objective of the preset study was to assess the occurrence of SSI and study the risk factors in oncologic surgeries of the digestive system at Hospital de Câncer in Barretos, São Paulo, Brazil. Individuals undergoing oncologic surgeries of the digestive system in the period of 08/01/2007 to $08 / 10 / 2008$ were prospectively followed for 30 days after surgery. Possible risk factors related to the patient and to the surgical procedure were also studied. A total of 210 surgeries were analyzed, with a global SSI incidence of $23.8 \%$. The following variables were independently associated with SSI: time and type of surgery, radiotherapy before surgery and surgeon's years of experience. The risk factors found in this study have been described by other authors and are not amenable to intervention for SSI prevention. Further studies are recommended with the objective of investigating interventions that could reduce the risk for SSI in this type of surgery.
\end{abstract}

Keywords: infection; surgical site; oncologic surgery; digestive system surgery.

[Braz J Infect Dis 2011;15(2):109-115]@Elsevier Editora Ltda.

\section{INTRODUCTION}

Midway through the twentieth century, it was believed that pain, anesthetic incidents, surgical wound infection and postoperative sepsis, which were important obstacles to the success of surgical treatment, had been overcome. In a way, such predictions came to pass; however, these complications are still around and persist as causes of postoperative morbidity and lethality. ${ }^{1-3}$

It is estimated that 500,000 cases of surgical-site infection (SSI) occur annually in the United States of America (USA) and, among the ranking of hospital infections, SSI is among the most frequent ones, contributing with $14 \%$ to $16 \%$ of the cases. ${ }^{1,3}$ However, among surgical patients, SSI is the hospital infection with the highest incidence, representing $38 \%$ of all infections in this population. ${ }^{1,4}$

SSI has a great impact on mortality, as $30 \%$ to $40 \%$ of the deaths in the postoperative period are caused by this infection. ${ }^{5}$ When patients with SSI die, the SSI itself is the cause of death, most cases (93\%) with severe infections involving organs and spaces. ${ }^{1}$ Another important consequence, with considerable impact for the healthcare system and society, is the impact on healthcare costs. ${ }^{1,5-7}$ In the USA, it is estimated that the annual excess costs due to SSI is $>1.6$ billion dollars. ${ }^{6}$ Among the factors that contribute the most to the cost increase is the length of hospital stay, with a described mean increase of 5.7 to 13.7 days. ${ }^{5,7-10}$ The need to prescribe antibiotics and perform reoperations as well as laboratory and radiologic assessments also has a considerable impact on healthcare expenditures. ${ }^{3,8}$

SSI is a multifactorial condition and the risk factors involved in its onset are common for most surgeries (age, obesity, surgical time, etc); however, other factors are peculiar to certain procedures. Thus, it is important to identify these factors to evaluate the procedures that carry the highest risk and, if possible, define adequate indices that can predict the risk of SSI in different types of surgery. ${ }^{11}$
Authors

Paulo de Tarso Oliveira e Castro $^{1}$

André Lopes Carvalho ${ }^{2}$ Stela Verzinhasse Peres ${ }^{3}$ Milene Mitsuyuki Foschini $^{4}$

Afonso Dinis Costa

Passos $^{5}$

${ }^{1}$ Infectologist , Hospital de Câncer de Barretos, São Paulo, Brazil

${ }^{2}$ Prof. Dr., Hospital de Câncer de Barretos, São Paulo, Brazil

${ }^{3}$ Epidemiologist, Hospital de Câncer de Barretos, São Paulo, Brazil

${ }^{4}$ Biostatistician, Hospital de Câncer de Barretos, São Paulo, Brazil

${ }^{5}$ Prof. Dr., Department of Social Medicine of Faculdade de Medicina de Ribeirão Preto, USP, São Paulo, Brazil

Submitted on: 3/8/2010 Approved on: 10/19/2010

Correspondence to: Paulo de Tarso Oliveira e Castro

Rua Antenor Duarte Villela, No 1331 14784-400, Barretos, SP, Brazil pitarso@terra.com.br

We declare no conflict of interest 
Hospital de Câncer in the town of Barretos, São Paulo State, Brazil, is specialized in oncology and performs around 6,000 surgeries annually, with approximately $11 \%$ being neoplasias of the digestive tract. In spite of the relevance of SSI, this is the first study of systematic collection of information on its distribution and characteristics in this hospital.

The study was approved by the Ethics Committee in Research of Hospital de Câncer de Barretos, process \# 95/07.

\section{METHODS}

Individuals aged 18 years and older, undergoing curative or palliative surgery for primary malignant neoplasias of the digestive system from August 1, 2007 to July 31,2008 , were enrolled in the study. Those who had not completed 30 days of postoperative follow-up were excluded, except cases of death due to SSI before completion of the 30-day period.

Information on the following variables were collected for each study participant: name, hospital registration number, age, sex, level of schooling, cancer type, neoplasia staging, diabetes mellitus, nutritional status and obesity, history of alcohol consumption, smoking status, surgery performed, date of surgery, surgical outcome (curative or palliative), surgical condition (elective or emergency), time of surgery, radiotherapy on the topography of the operative field prior to surgery, chemotherapy prior to surgery, hyperglycemia in the perioperative period, polytransfusion of blood derivatives in the perioperative period, antibiotic prophylaxis (antibiotic agent used, dose, moment of start, intraoperative repeat dosing and duration of use), length of preoperative hospitalization, surgical team, surgeon's years of experience, ASA classification, type of anesthesia, potential for surgery contamination, SSI data (date of diagnosis, depth, microbial etiology, evolution). The CDC criteria $^{11}$ were used to diagnose SSI.

The information were stored in a database and analyzed using the software SPSS for Windows, release 17.0.

First, the sample was characterized by absolute and relative frequencies, central tendency measures (mean and median) and dispersion (range and standard deviation). For quantitative variables, adherence to the normal curve was verified by the Kolmogorov-Smirnov test. As the variables did not have a normal distribution, the non-parametric Mann-Whitney test was applied to compare the groups with and without SSI. Association between independent qualitative variables and SSI was initially assessed through univariate analysis using the Chi-square test or Fisher's exact test when indicated.

Subsequently, multiple logistic regression models were used to verify the independent association between the studied variables and SSI. A p-value $\leq 0.25$ was the cut-off used to determine which variables would enter the multivariate model. Statistical significance was set at $\alpha=5 \%$.

\section{RESULTS}

Of the 224 potential participants, 14 patients were excluded: seven did not complete the 30-day follow-up, five did not have cancer, and two for reoperation due to non-infectious surgical complications before the end of the 30-day period. Therefore, the final sample consisted of 210 individuals.

Among participants, 59.5\% (125/210) were male and $50 \%$ were less than 60 years old. As for the nutritional status, 7\% (14/210) were malnourished, 48\% (97/210) were overweight/obese, and 45\% (91/210) had normal weight. Up to $14.6 \%(30 / 205)$ had diabetes mellitus, $23 \%$ $(48 / 160)$ were smokers, and $15.6 \%(32 / 205)$ reported history of alcohol consumption. The ASA score was defined in 204 participants and, of these, $30.9 \%$ were classified as ASA $1,56 \%$ as ASA 2 and $12.7 \%$ as ASA $3 / 4$. Neoplasia staging was assessed in 192 individuals, with 89 (46.4\%) being classified as stages I/II and the remaining as stages III//IV.

Regarding the type of surgery (Table 1), 12.9\% (27/210) were derivations/jejunum, 23.8\% (50/210) were of the upper digestive system and $63.3 \%$ (133/210) of the lower digestive tract. SSI was diagnosed in 50 surgeries (23.8\%) and most were classified as superficial (46\%). Deep infections and infections of organs and spaces

Table 1. Distribution of participants according to the characteristics of the surgery and anesthesia, ICU stay and development of surgical site infection

\begin{tabular}{lccc}
\hline Variables & Categories & n & \% \\
\hline Type of & Jejunum/derivation & 27 & 12.9 \\
surgery & Upper digestive & 50 & 23.8 \\
& Lower digestive & 133 & 63.3 \\
\hline Potential for & Potentially contaminated & 70 & 33.3 \\
contamination & Contaminated/infected & 140 & 66.7 \\
\hline Days at ICU** & Up to 2 days & 18 & 40.0 \\
& 3 days or more & 27 & 60.0 \\
\hline Type of & General & 59 & 28.4 \\
anesthesia* & Spinal + epidural & 25 & 12.0 \\
& Spinal + general & 124 & 59.6 \\
\hline Previous & No & 111 & 58.4 \\
surgery* & Yes & 79 & 41.6 \\
\hline Surgical site & No & 160 & 76.2 \\
infection & Superficial & 23 & 11.0 \\
& Deep & 10 & 4.8 \\
\hline Total & Organs and spaces & 17 & 8.1 \\
\hline & & 210 & 100 \\
\hline Som & & & \\
\hline
\end{tabular}

*Some values are unknown for some participants.

$* *$ Only patients that needed ICU. 
represented, respectively, $20 \%$ and $34 \%$ of the total. There was a predominance of contaminated/infected surgeries (66.7\%), ICU stay $\geq 3$ days $(60 \%)$, absence of previous surgery $(58.4 \%)$, and combination of spinal and general anesthesia (59.6\%). The mean time between surgery and SSI diagnosis was 11.9 days.

Surgical antibiotic prophylaxis was prescribed in $99.5 \%$ of the surgeries and its use was adequate in $74.5 \%$ of them. The most common inadequacy was the use of a lower than recommended dose (10.1\%). On the other hand, there was a high rate of appropriateness regarding the antibiotic agent selected, moment of prophylaxis initiation, intraoperative repeat doses and prophylaxis period (Table 2).

As for the etiology of SSI, it was not possible to identify the agent in 15 patients, as material for laboratory analysis was not collected before the start of antibiotics or the surgical procedure for treating the infection. Therefore, $70 \%$ of the SSI were microbiologically confirmed (35/50). Gram-negative bacteria were most frequently isolated, totaling 31 cases with Escherichia coli being the most prevalent. Bacteria considered multiresistant to antimicrobial agents were isolated from only seven cases, mainly oxacillin-resistant Staphylococcus aureus. Anaerobic microorganisms were not isolated as the Microbiology Laboratory of of Hospital de Câncer de Barretos does not have the methodology to isolate these pathogens.

Among SSI patients, three died, two due to the underlying neoplasia and one attributed to SSI itself, thus resulting in a SSI lethality rate of $2 \%(1 / 50)$.

Statistical analysis of the quantitative variables ( $\mathrm{Ta}-$ ble 3) showed that only time of surgery was significantly higher among SSI patients, when compared to those without SSI $(p=0.007)$. The logistic regression analysis is summarized in Table 4, showing the following variables that presented a significant independent association with SSI: contaminated/infected surgery, lower digestive surgery, adjuvant treatment (chemotherapy and/or
Table 2. Adequacy of the parameters in the individuals that received antibiotic prophylaxis

\begin{tabular}{lccc}
\hline Variables & Categories & n & \% \\
\hline Use of prophylactic & Yes & 209 & 99,5 \\
antibiotic agents & No & 1 & 0,5 \\
\hline Choice of & Adequate & 206 & 99,0 \\
antibiotic agent & Inadequate & 2 & 1,0 \\
\hline Start of & Before surgery & 187 & 92,6 \\
antibiotic therapy & During surgery & 15 & 7,4 \\
\hline Intraoperative & Yes & 29 & 13,9 \\
repeat dosing & No & 11 & 5,3 \\
& Not indicated & 168 & 80,8 \\
\hline Dose & Adequate & 178 & 89,9 \\
& Inadequate & 20 & 10,1 \\
\hline Period of & Single dose & 64 & 30,9 \\
prophylaxis & Intra-operative & 16 & 7,7 \\
& Up to 24 hours & 118 & 57,0 \\
& 24 to 48 hours & 1 & 0,5 \\
& $\geq 48$ hours & 8 & 3,9 \\
\hline Prophylactic & not adequate & 49 & 25,5 \\
antibiotics (all & adequate & 143 & 74,5 \\
parameters together) & & & \\
\hline Total & & 210 & 100,0 \\
\hline
\end{tabular}

radiotherapy before surgery), and surgeon's less years of experience. The analysis of the surgeon's years of experience did not show a correlation with the time of surgery $(p=0.45)$. At the multivariate analysis adjusted for the presence of diabetes mellitus (Table 5) the variables that had an independent significant association with SSI were: surgeon's experience $<10$ years, chemotherapy and/or radiotherapy before surgery and surgery duration.

Type of surgery (contaminated or infected) was at the threshold of statistical significance.

Table 3. Descriptive statistics of the time of surgery, body mass index (BMI) and age according to the presence of SSI

\begin{tabular}{|c|c|c|c|c|c|c|c|c|c|}
\hline \multirow[t]{2}{*}{ Variables } & \multicolumn{4}{|c|}{ Presence of SSI } & \multicolumn{5}{|c|}{ Absence of SSI } \\
\hline & $\mathbf{n}$ & $\begin{array}{l}\text { Mean } \\
\text { (SD) }\end{array}$ & Median & Range & $\mathbf{n}$ & $\begin{array}{l}\text { Mean } \\
\text { (SD) }\end{array}$ & Median & Range & $\mathbf{p}^{*}$ \\
\hline $\begin{array}{l}\text { Time of } \\
\text { surgery (min) }\end{array}$ & 50 & $205.4(85.7)$ & 192.5 & $30-420$ & 160 & $169.8(82.1)$ & 160.00 & $25-420$ & 0.007 \\
\hline BMI $\left(\mathrm{kg} / \mathrm{m}^{2}\right)$ & 48 & $25.1(4.8)$ & 25.2 & $14.7-40.1$ & 151 & $25.3(4.9)$ & 24.8 & $14.5-42.5$ & 0.867 \\
\hline Age (years) & 50 & $59.1(12.9)$ & 60.0 & $33-81$ & 160 & $59.3(13.5)$ & 59.0 & $25-85$ & 0.921 \\
\hline
\end{tabular}

*Mann-Whitney. 
Table 4. Univariate logistic regression analysis according to the presence of surgical-site infection

\begin{tabular}{|c|c|c|c|c|c|c|}
\hline Variables & Categories & $\begin{array}{l}\text { Infection } \\
\text { n (\%) }\end{array}$ & $\begin{array}{l}\text { Total } \\
\text { n (\%) }\end{array}$ & $\mathbf{p}\left(\chi^{2}\right)$ & OR $_{\text {crude }}$ & 95\% CI \\
\hline \multirow{2}{*}{$\begin{array}{l}\text { Potential for } \\
\text { contamination }\end{array}$} & Potentially contaminated & $7(10.0)$ & $70(100)$ & \multirow[t]{2}{*}{0.001} & 1.0 & \\
\hline & Contaminated/infected & $43(30.7)$ & $140(100)$ & & 3.99 & $1.689-9.423$ \\
\hline \multirow[t]{3}{*}{ Type of surgery } & Jejunum/derivation & $1(3.7)$ & $27(100)$ & \multirow[t]{3}{*}{0.001} & 1.0 & \\
\hline & Upper digestive & $6(12.0)$ & $50(100)$ & & 3.54 & $0.404-31.108$ \\
\hline & Lower digestive & $43(32.3)$ & $133(100)$ & & 12.42 & $1.631-94.591$ \\
\hline \multirow[t]{2}{*}{ Previous surgery } & No & $31(27.9)$ & $111(100)$ & \multirow[t]{2}{*}{0.316} & 1.0 & \\
\hline & Yes & $17(21.5)$ & $79(100)$ & & 0.71 & $0.359-1.394$ \\
\hline \multirow[t]{2}{*}{ Clinical staging } & $\mathrm{I} / \mathrm{II}$ & $23(25.8)$ & $89(100)$ & \multirow[t]{2}{*}{0.465} & 1.0 & \\
\hline & III/IV & $22(21.4)$ & $103(100)$ & & 0.78 & $0.399-1.521$ \\
\hline \multirow[t]{2}{*}{ ASA classification } & 1 and 2 & $48(27.0)$ & $178(100)$ & \multirow[t]{2}{*}{0.048} & 1.0 & \\
\hline & $>2$ & $2(7.7)$ & $26(100)$ & & 0.23 & 0.051-0.991 \\
\hline \multirow{2}{*}{$\begin{array}{l}\text { Adequate antibiotic } \\
\text { prophylaxis }\end{array}$} & No & $8(16.3)$ & $49(100)$ & \multirow[t]{2}{*}{0.238} & 1.0 & \\
\hline & Yes & 35 (24.5) & $143(100)$ & & 1.66 & $0.711-3.878$ \\
\hline \multirow[t]{2}{*}{ Adjuvant treatment } & No & 32 (19.3) & $166(100)$ & \multirow[t]{2}{*}{0.003} & 1.0 & \\
\hline & Yes & $18(40.9)$ & $44(100)$ & & 2.89 & $1.420-5.921$ \\
\hline \multirow{3}{*}{$\begin{array}{l}\text { Time of surgeon's } \\
\text { experience }\end{array}$} & $>10$ & $13(14.0)$ & $93(100)$ & \multirow[t]{3}{*}{$<0.001$} & 1.0 & \\
\hline & 5 to 10 & $31(30.4)$ & $102(100)$ & & 2.68 & $1.305-5.532$ \\
\hline & $<5$ & $6(40.0)$ & $15(100)$ & & 4.10 & $1.251-13.454$ \\
\hline \multirow[t]{2}{*}{ Days in ICU } & Up to 2 days & $2(11.1)$ & $18(100)$ & \multirow[t]{2}{*}{0.684} & 1.0 & \\
\hline & 3 days or more & $5(18.5)$ & $27(100)$ & & 1.82 & $0.312-10.586$ \\
\hline
\end{tabular}

Table 5. Multivariate logistic regression analysis according to the presence of surgical-site infection

\begin{tabular}{|c|c|c|c|c|}
\hline Variables & Categories & OR $_{\text {adjusted }}$ & 95\% CI & p \\
\hline \multirow[t]{2}{*}{ Type of surgery } & $\begin{array}{c}\text { Potentially } \\
\text { contaminated }\end{array}$ & 1.0 & & \\
\hline & Contaminated/infected & 2.68 & $0.998-7.218$ & 0.050 \\
\hline \multirow{2}{*}{$\begin{array}{l}\text { Chemo/radiotherapy } \\
\text { before surgery }\end{array}$} & Yes & 2.54 & $1.150-5.615$ & 0.021 \\
\hline & No & 1.0 & & \\
\hline Time of surgery* & & 1.005 & $1.001-1.009$ & 0.026 \\
\hline \multirow{3}{*}{$\begin{array}{l}\text { Time of surgeon's } \\
\text { experience }\end{array}$} & $<5$ & 4.502 & $1.269-15.972$ & 0.020 \\
\hline & 5 to 10 & 1.982 & $0.861-4.563$ & 0.108 \\
\hline & $>10$ & 1.0 & & \\
\hline
\end{tabular}

**Adjusted by diabetes mellitus.

*Treated as continuous variable.

\section{DISCUSSION}

The observed incidence of SSI in the present study was $23.8 \%$. As the incidence from previous reports in the pertinent literature has a great deal of variability, the SSI incidence observed at our hospital would sometimes be considered higher and sometimes lower. However, it must be emphasized that few studies included only oncologic surgeries. ${ }^{9,12-19}$
Smith et al. ${ }^{19}$ reported an incidence of SSI of $25.6 \%$; however, they assessed only incision infections (superficial and deep) in patients undergoing colorectal resections, either oncologic or not. Konishi et al. ${ }^{13}$ also studied only incision infections (superficial and deep) in colon and rectal surgeries, having found incidences of $9.4 \%$ and $18.0 \%$, respectively $(\mathrm{p}=0.003)$. Velasco et al. ${ }^{18}$ found an incidence of SSI of 
$22.4 \%$ in oncologic abdominal surgeries, whereas Oliveira et al. ${ }^{14}$ reported an incidence of $22.1 \%$ in gastric surgeries, either oncologic or not. Imai et al..$^{12}$ studied 1,116 oncologic open gastric surgeries and found an incidence of $13.8 \%$, with time of surgery being verified as the only risk factor. Another study by Vilar-Compte et al. ${ }^{16}$ investigated the SSI incidence in oncologic surgeries of seven specialties. Overall, the SSI rate was $9.3 \%$, being as high as $14.1 \%$ in digestive system surgeries. The main associated risk factors were diabetes mellitus, obesity and presence of a drain for more than five days.

The findings of the present study confirmed the knowledge that surgeries with higher microbial load in the operative field is associated with higher risk of SSI, ${ }^{1,8,20}$ considering that surgeries of the lower digestive system (contaminated) had an incidence of $32.3 \%$, whereas those of the upper digestive system had $12 \%$. In lower digestive system surgeries, the incidence found in Barretos was higher than that observed by Smith et al. ${ }^{19}$ and Konish et al.,$^{13}$ although it must be recalled that these authors did not account for organ and space infections when they studied oncologic and non-oncologic surgeries. The latter study found that the incidence of SSI was almost two-fold higher in rectal surgeries (18\%) than in colon surgeries $(9.4 \%)$, which emphasizes the importance of performing a detailed analysis by procedure, as the risk can vary even in situations with similar microbial load in the operative field.

In upper digestive system surgeries, the incidence of SSI in the present investigation (12\%) was lower than the one reported by Oliveira et al. ${ }^{14}$ Velasco et al. ${ }^{18}$ and Imai et al. ${ }^{12}$ albeit higher than that reported by the National Nosocomial Infection Surveillance System (NNIS). ${ }^{15}$

The comparison of SSI incidence between hospitals from different locations and countries must always be carefull, as there are specific characteristics for each place and patient population that make it difficult to reach valid conclusions. The ideal situation would be for each hospital to critically analyze its own data, preferably focusing such analysis on the historical series and particularizing it for the several types of surgery.

In the present study, the variables that had a statistical association with SSI (type of surgery, surgeon's experience, duration of surgery and chemo/radiotherapy before the surgery) are risk factors that have been previously reported by other authors in different investigations. . $214,17,18,21-23^{-1}$

Of the neoplasms assessed in the present study, chemotherapy/radiotherapy before the surgical procedure is only indicated for lower rectal tumors. This might be a confounding variable, as surgeries with resection of the rectum already have an increased risk of infection due to the high microbial load present in the operative field, in addition to the low anastomosis, close to the anal border, thus considered of high risk for dehiscence and SSI. ${ }^{13}$ However, the as- sociation was maintained even at the multivariate analysis, showing this is an independent risk factor in the present investigation.

The use of neoadjuvant chemotherapy/radiotherapy for rectal neoplasia is associated with better treatment results; however, it increases the risk of SSI and other complications. ${ }^{13,18,24}$ This is mainly determined by radiotherapy, as the surgery is carried out after the conclusion of the adjuvant therapy and, obviously, outside the period of neutropenia and mucositis that can be induced by chemotherapy. On the other hand, radiotherapy causes several local tissue damages, which are very often irreversible, such as vascular lesions that lead to ischemia and compromise the venous return and lymphatic drainage, decreasing oxygen supply to the irradiated tissues and, consequently, local defenses. ${ }^{13,24}$

The present study is also in accordance with the literature regarding the risk of SSI determined by the duration of the surgery. ${ }^{912-14,23}$ Longer interventions increase the risk of SSI as they cause higher tissue exposure, as well as surgeries that present higher technical complexity or take longer due to accidents and complications (hypotension, hemorrhage, etc). All these conditions provide better opportunity for microbial invasion of tissues and the subsequent development of infection.

A good surgical technique is recognized to be one of the main SSI prevention measures. ${ }^{1,22}$ Adequate homeostasis, with maintenance of tissue perfusion, careful handling/dissection of tissues, devitalized tissue removal and careful use of the electrocautery are considered critical points, among others. Both the technique and the surgeon's skills are difficult to assess.

Generally, the technique/skill is inferred by the surgery duration and the incidence of complications such as SSI and reoperation, to mention a few. It is known that the learning curve for the performance of surgical procedures can be long and demand a great deal of training, and little is known about the necessary time for a surgeon to reach the apex for performing a certain type of intervention. Nevertheless, most studies do not assess the impact of the the surgeon's years of experience on the incidence of SSI. A study by Wurtz et al..$^{25}$ assessed this variable and found a significant difference in the SSI incidence between less experienced and more experienced surgeons ( $\mathrm{p}<0.05)$, after adjusting for possible confounders. Muilwijk et al. ${ }^{26}$ evaluated the risk of SSI based on the surgical volume, comparing hospitals and surgeons. The surgeries that were part of this study were radical mastectomy, colon resection, appendectomy, total abdominal hysterectomy, Cesarean section, partial femoral arthroplasty, femoral arthroplasty review and knee arthroplasty. No difference was observed in the SSI incidence among the different hospitals; however, the surgeons who performed the least number of procedures also had the longest time of surgery and had a tendency towards higher incidence of SSI. 
The authors concluded that surgeons should be made aware of the increased risk of SSI when performing procedures that were not frequent in their clinical practice. ${ }^{26}$

The ASA score evaluates the basal condition of individuals and their comorbidities and, therefore, it is also a good predictor for SSI. This association has been demonstrated by several authors. However, it has not been observed in the town of Barretos, where the incidence of SSI in individuals that had ASA > II was 7.7\% (2/26), versus $27 \%(48 / 178)$ in individuals with ASA $\leq$ II. When analyzing the association between ASA score and time of surgery, it was observed that $26.4 \%$ of the individuals (47/178) with ASA $\leq$ II, the surgery duration was $>235$ minutes (75th percentile), whereas the same duration occurred in only $11.5 \%(3 / 26)$ of the individuals with ASA > II. It is also noteworthy that $21.5 \%(38 / 177)$ of individuals with ASA $\leq$ II were submitted to palliative surgery, whereas $34.6 \%(9 / 26)$ of the individuals with ASA III or IV were submitted to this type of surgery. Possibly, individuals with more comorbidities had the highest risk of surgical complications and thus, were submitted to less aggressive and more conservative surgeries, of shorter durations. The small sample size, with only 26 participants classified as ASA > II, might also have influenced the findings of the present investigation.

Some questions were not addressed in the Barretos study. Among them, the moment of hair removal, as it is a routine procedure in the hospital to perform with an electric shaver in the operation room, immediately before degermation and aseptic techniques are carried out in the operative field.

This investigation has several limitations. One is the lack of assessment in colon and rectum resections (lower digestive system) and whether the colostomy or ileostomy had an impact on the incidence of SSI. Similarly, we did not assess the role of the persistence of cavity drainage and mainly, the type of drainage used. Additionally, it was assessed in the current study the quality of intestinal preparation in surgeries that needed such preoperative procedure and the occurrence of accidents/complications (hypotension, hypothermia, etc) during the procedure. Although it is a routine at Hospital de Câncer de Barretos to perform a preoperative bath, adherence to the procedure and its possible interference with the onset of SSI was not studied. Other variables, equally not studied, included the impact of SSI on the hospitalization time, the need for reoperations and rehospitalizations and the increase in healthcare costs.

\section{CONCLUSION}

The following risk factors for SSI were identified in oncologic surgeries of the digestive system: type of surgery, potential for contamination of the surgical wound, time of surgery, neoadjuvant radiotherapy applied to the operative field, and surgeon's years of experience. Such factors describe a group of individuals at a higher risk for the development of SSI, for whom new prevention protocols must be considered.

\section{ACKNOWLEDGEMENTS}

We would like to thank Ms. Allini Mafra da Costa and Mr. Thiago Buosi Silva for their essential collaboration in typing, tabulating and analyzing data; and Dr. Vinicius de Lima Vazques, Dr. Armando Geraldo F. Melani and Dr. José Humberto Tavares G. Fregnani, for their valuable suggestions.

\section{REFERENCES}

1. Mangram AJ, Horan TC, Pearson ML, Silver LC, Jarvis WR. Guideline for prevention of surgical site infection, 1999. Hospital Infection Control Practices Advisory Committee. Infect Control Hosp Epidemiol. 1999; 20(4):25078; quiz 79-80.

2. Haynes $A B$, Weiser TG, Berry WR et al. A surgical safety checklist to reduce morbidity and mortality in a global population. N Engl J Med. 2009; 360(5):491-9.

3. Bratzler DW, Hunt DR. The surgical infection prevention and surgical care improvement projects: national initiatives to improve outcomes for patients having surgery. Clin Infect Dis. 2006; 43(3):322-30.

4. Martone WJ, Nichols RL. Recognition, prevention, surveillance, and management of surgical site infections: introduction to the problem and symposium overview. Clin Infect Dis. 2001; 33 Suppl 2:S67-8.

5. Kirkland KB, Briggs JP, Trivette SL, Wilkinson WE, Sexton DJ. The impact of surgical-site infections in the 1990s: attributable mortality, excess length of hospitalization, and extra costs. Infect Control Hosp Epidemiol. 1999; 20(11):725-30.

6. de Lissovoy G, Fraeman K, Hutchins V, Murphy D, Song D, Vaughn BB. Surgical site infection: incidence and impact on hospital utilization and treatment costs. Am J Infect Control. 2009; 37(5):387-97.

7. Gaynes RP. Surveillance of surgical-site infections: the world coming together? Infect Control Hosp Epidemiol. 2000; 21(5):309-10.

8. Fry DE, Fry RV. Surgical site infection: the host factor. AORN J. 2007; 86(5):801-10; quiz 11-4.

9. de Oliveira AC, Ciosak SI. Infecção de sítio cirúrgico em hospital universitário: vigilância pós-alta e fatores de risco. Rev Esc Enferm USP. 2007; 41(2):258-63.

10. Alves A, Panis Y, Mantion G, Slim K, Kwiatkowski F, Vicaut E. The AFC score: validation of a 4 -item predicting score of postoperative mortality after colorectal resection for cancer or diverticulitis: results of a prospective multicenter study in 1049 patients. Ann Surg. 2007; 246(1):91-6

11. Ercole FF, Starling CE, Chianca TC, Carneiro M. Applicability of the national nosocomial infections surveillance system risk index for the prediction of surgical site infections: a review. Braz J Infect Dis. 2007; 11(1):134-41.

12. Horan TC, Gaynes RP, Martone WJ, Jarvis WR, Emori TG. CDC definitions of nosocomial surgical site infections, 1992; a modification of CDC definitions of surgical wound infections. Infect Control Hosp Epidemiol. 1992; 13(10):606-08

13. Imai E, Ueda M, Kanao K, Miyaki K, Kubota T, Kitajima M. Surgical site infection surveillance after open gastrectomy and risk factors for surgical site infection. J Infect Chemother. 2005; 11(3):141-5. 
14. Konishi T, Watanabe T, Kishimoto J, Nagawa H. Elective colon and rectal surgery differ in risk factors for wound infection: results of prospective surveillance. Ann Surg. 2006; 244(5):75863.

15. de Oliveira AC, Ciosak SI, Ferraz EM, Grinbaum RS. Surgical site infection in patients submitted to digestive surgery: risk prediction and the NNIS risk index. Am J Infect Control. 2006; 34(4):201-7.

16. Gaynes RP, Culver DH, Horan TC, Edwards JR, Richards C, Tolson JS. Surgical site infection (SSI) rates in the United States, 1992-1998: the National Nosocomial Infections Surveillance System basic SSI risk index. Clin Infect Dis. 2001; 33 Suppl 2:S69-77.

17. Vilar-Compte D, Mohar A, Sandoval S, Rosa M, Gordillo P, Volkow P. Surgical site infections at the National Cancer Institute in Mexico: A case-control study. Am J Infect Control. 2000; 28(1):14-20.

18. Velasco E, Santos LC, de Souza Martins CA, de Castro Dias LM, da S.e C. Gonçalves VM. Risk index for prediction of surgical site infection after oncology operations. Am J Infect Control. 1998; 26(3):217-23.

19. Velasco E, Thuler LCS, de Souza Martins CA, de Castro Dias LM, da S.e C. Gonçalves VM. Risk factors for infections complications after abdominal surgery for malignant disease. Am J Infect Control. 1996; 24(1):1-6.

20. Smith RL, Bohl JK, McElearney ST et al. Wound infection after elective colorectal resection. Ann Surg. 2004; 239(5):599-605; discussion -7 .
21. Platell C, Hall JC. The prevention of wound infection in patients undergoing colorectal surgery. J Hosp Infect. 2001; 49(4):233-8.

22. Delgado-Rodriguez M, Gomez-Ortega A, Sillero-Arenas M, Llorca J. Epidemiology of surgical-site infections diagnosed after hospital discharge: a prospective cohort study. Infect Control Hosp Epidemiol. 2001; 22(1):24-30.

23. Dominioni L, Imperatori A, Rotolo N, Rovera F. Risk factors for surgical infections. Surg Infect (Larchmt). 2006; 7 Suppl 2:S9-12.

24. Imai E, Ueda M, Kanao K et al. Surgical site infection risk factors identified by multivariate analysis for patient undergoing laparoscopic, open colon, and gastric surgery. Am J Infect Control. 2008; 36(10):727-31.

25. Turina M, Mulhall AM, Mahid SS, Yashar C, Galandiuk S. Frequency and surgical management of chronic complications related to pelvic radiation. Arch Surg. 2008; 143(1):46-52; discussion

26. Wurtz R, Wittrock B, Lavin MA, Zawacki A. Do new surgeons have higher surgical site infection rates? . Infect Control Hosp Epidemiol. 2001; 22:000-.

27. Muilwijk J, Hof S, Wille JC. Associations Between Surgical Site Infection Risk and Hospital Operation Volume and Surgeon Operation Volume Among Hospitals in the Dutch Nosocomial Infection Surveillance Network. Infect Control Hosp Epidemiol. 2007; 28(5):557-63. 